\title{
Prevención de la lumbalgia asociada a tareas que implican levantar peso
}

Back pain prevention in jobs that involve heavy lifting

\section{Objetivo}

Revisar la evidencia científica sobre la efectividad del entrenamiento y el uso de dispositivos de elevación para prevenir el dolor lumbar en trabajadores involucrados en el levantamiento de peso.

\section{Fuentes de datos}

Embase, Central, Sinal, Nioshtic, CISdoc, Science Citation Index, PschLIT, Medline y Registro de Ensayos del Grupo Cochrane (Trastornos de Columna) hasta noviembre de 2005. Incluyeron ensayos controlados aleatorizados con un seguimiento de seis meses a cinco años y cohortes con grupo control, con ocho semanas a dos años de seguimiento.
Martimo K y col. BMJ 2008; 336; 429-431.

\section{Selección de estudios y extracción de datos}

Seis investigaciones aleatorizadas -sólo dos de ellas de buena calidad metodológica- y cinco cohortes -las cinco de buena calidad- cumplieron con los criterios de inclusión, todas ellas centrados en la prevención del dolor lumbar. Fueron evaluadas las siguientes intervenciones: técnicas de entrenamiento de la postura, uso de equipos de apoyo y de sostén (fajas o cinturones posteriores) técnicas de elevación y prácticas de cuidado a la hora de movilizar pacientes.

\section{Resultados principales}

Luego de un análisis fundamentalmente descriptivo y cualitativo, la tabla 1 resume los resultados más relevantes de los cuatro ensayos aleatorizados que reportaron datos.

Tabla 1: efectividad de algunas intervenciones para prevenir la aparición de nuevos episodios de dolor o injuria lumbar en diferentes poblaciones, según los datos reportados por cuatro ensayos aleatorizados.

\begin{tabular}{|c|c|c|c|c|c|c|}
\hline Intervención & $\begin{array}{l}\text { Autor, alío y duración } \\
\text { del seguimiento }\end{array}$ & $\begin{array}{c}\text { Galidad } \\
\text { metodológica }\end{array}$ & $\begin{array}{l}\text { Resultado evaluado como } \\
\text { incidencia de: }\end{array}$ & Interv. & Control & OR (I695\%) \\
\hline \multirow{2}{*}{$\begin{array}{c}\text { Consejo sobre elevación y } \\
\text { manipulación de } \\
\text { objetos vs. } \\
\text { no intervención }\end{array}$} & $\begin{array}{c}\text { Van Poppel }{ }^{\mathrm{a}}, 1998 \\
\text { (s eis meses) }\end{array}$ & Buena & \multirow[t]{2}{*}{ Dolor o injuria lumbar } & \multirow[t]{2}{*}{$32 / 108$} & \multirow[t]{2}{*}{$32 / 109$} & \multirow[t]{2}{*}{$\begin{array}{c}0,99 \\
(0,54 \text { a } 1,81)\end{array}$} \\
\hline & $\begin{array}{c}\text { Yassi }{ }^{\mathrm{b}}, 2001 \\
\text { (12 meses) }\end{array}$ & Mala & & & & \\
\hline $\begin{array}{l}\text { Consejo vs. } \\
\text { uso de faja }\end{array}$ & $\begin{array}{r}\text { Krauss }^{c}, 2002 \\
(28 \text { meses })\end{array}$ & Mala & Dolor 0 injuria lumbar & $1 / 29$ & $1 / 30$ & $\begin{array}{c}1,04 \\
(0,06 \text { a } 17,38)\end{array}$ \\
\hline $\begin{array}{c}\text { Consejo mayor } \\
\text { vs. mínimo } \\
\end{array}$ & $\begin{array}{c}\text { Deltroy }^{\mathrm{d}}, 1997 \\
(5,5 \text { a os }) \\
\end{array}$ & Buena & Injuria lumbar & $18 / 820$ & $18 / 881$ & $\begin{array}{c}1,08 \\
(0,56 \text { a } 2,08) \\
\end{array}$ \\
\hline
\end{tabular}

a Manipuladores de carga sometidos a tres sesiones de 1,5 a 2 dos horas de duración. Enfermeros sometidos a una sesión de $2 \mathrm{~h}$ de duración.

'Trabajadores hogareños. ' Trabajadores postales sometidos a dos sesiones de 1,5 horas de duración.

\section{Conclusiones}

No existe evidencia para respaldar en trabajadores involucrados en tareas que implican levantar peso, la implementación de intervenciones basadas en consejo o entrenamiento -acompañadas o nó de equipos de sostén-, con el objetivo de prevenir la apari- ción de dolor lumbar o su consecuente discapacidad.

Palabras clave: lumbalgia, prevención, trabajadores manuales. Key words: back pain, prevention, manual workers.

Fuente de financiamiento: Australian Safety and Compensation Council.

\section{Comentario}

La lumbalgia laboral tiene un origen multifactorial. Los aspectos físicos o mecánicos influirían fundamentalmente en la aparición del dolor, y los psicosociales en la repercusión de dicho síntoma en forma de incapacidad física y/o ausentismo laboral. Muchos profesionales de la salud están involucrados en la aplicación de programas que enseñan a los trabajadores técnicas eficaces para prevenir el dolor lumbar y sus consecuencias, así como en la selección de elementos ergonómicos para minimizar la carga que soportan la columna vertebral y su musculatura durante la jornada laboral.

Si bien, ninguno de los estudios identificados por los autores de estar revisión -que incluyeron diferentes poblaciones, diseños y calidades metodológicas- pudo documentar la efectividad de intervenciones para prevenir lesiones asociadas al trabajo manual; estos hallazgos podrían estar limitados por el bajo poder de la mayoría de las investigaciones identificadas.
Por ejemplo y como muestra la tabla 1 , con excepción de dos de los ensayos ${ }^{1}$, los grupos comparados (intervención y control) involucraron un pequeñísimo número de individuos. Por otro lado, lamentablemente, la mayoría de las publicaciones a las que accedieron los revisores no describió adecuadamente el contexto en el que fue instaurada la intervención.

\section{Conclusiones del comentador}

Esperamos por lo tanto, publicaciones de mejor calidad que permitan responder la enorme cantidad de dudas que todavía existen en esta área de la prevención, incluyendo investigaciones referidas a comprender los mecanismos multi-causales de génesis y mantenimiento del dolor lumbar asociado a tareas laborales.

Haydée Giraudi [ Médica Laboral, Servicio de Medicina Familiar y Preventiva del Hospital Italiano de Buenos Aires. haydee.giraudi@ hospitalitaliano.org.ar ]

Recibido el 20/08/08 y aceptado el 28/10/08.

Giraudi H. Prevención de la lumbalgia asociada a tareas que implican levantar peso. Evid. actual. práct. ambul; 11(5): 134 Sep-Oct.2008. Comentado de: Martimo y col. Effect of training and lifting equipment for preventing back pain in lifting and hadling: systematic review. BMJ 2008; 336; 429-431. PMID: 18244957. Disponible en URL: http://www.bmj.com/cgi/content/full/336/7641/429 (último acceso 28/10/08). 